\title{
Prevalence and healthcare seeking practice of work-related musculoskeletal disorders among informal sectors of hairdressers in Ethiopia, 2019: findings from a cross- sectional study
}

Tesfaye Hambisa Mekonnen ${ }^{1 *}$, Getachew Guteta Kekeba², Jember Azanaw and Gebisa Guyasa Kabito

\begin{abstract}
Background: Work-related musculoskeletal disorders (MSDs) are the major threats to public health, with a significant impact on workers, employers, and the general population. Musculoskeletal disorder related to work not only results in adverse health effects such as physical injury, disability, and a reduction in workers' quality of life, but it also places immense burdens on the use of healthcare facilities and a substantial loss of productivity. The purpose of this research was to discover the prevalence and associated factors of work-related MSDs among hairdressers in Oromia Special Zone Surrounding Finfine, Ethiopia.
\end{abstract}

Methods: A cross-sectional survey was carried out between March and April 2019. We included a total of 699 hairdressers with a systematic random sampling technique. Work-related MSDs was evaluated with the standardized Nordic Musculoskeletal survey, and the survey was administered by the interviewer. We employed SPSS version 20 software to perform a bivariate and multivariate analysis. A $p$-value of $<0.05$ was considered a significant association.

Results: In total, 652 hairdressers were interviewed with a response rate of 93.2\%. Participants' mean age was 33.19 (SD \pm 9.639$)$ years. The prevalence of work-related MSDs was $70.2 \%(N=458)[95 \% \mathrm{Cl}(66.7,73.9)]$ and $55.7 \%$ in the past 12-months and 7 days, respectively. The study showed the highest prevalence rate was observed in shoulder 53.7\% ( $n=350)$ followed by 53.4\% $(n=348)$ neck and 53.2\% $(n=347)$ low back. Of the participants, $33.4 \%(n=153)$ perceived their pain to be severe whereas $28 \%(n=128)$ a high disabling. Almost one-third $(n=187)$ of the respondents used healthcare services. Age $[A O R=2.73 ; 95 \% \mathrm{Cl}(2.55,5.46)]$, work experience $[A O R=1.51 ; 95 \% \mathrm{Cl}$ $(1.03,2.20)]$, number of customers served per day $[A O R=2.35 ; 95 \% \mathrm{Cl}(1.35,4.11)]$, and hours spent standing to make hair $[\mathrm{AOR}=3.4 ; 95 \% \mathrm{Cl}(2.49,7.77)]$ were significantly associated factors.

* Correspondence: tajan2022@gmail.com

'Department of Environmental and Occupational Health and Safety, Institute of Public Health, College of Medicine and Health Sciences, University of Gondar, P.O. Box. 196, Gondar, Ethiopia

Full list of author information is available at the end of the article

(c) The Author(s). 2020 Open Access This article is licensed under a Creative Commons Attribution 4.0 International License, which permits use, sharing, adaptation, distribution and reproduction in any medium or format, as long as you give appropriate credit to the original author(s) and the source, provide a link to the Creative Commons licence, and indicate if changes were made. The images or other third party material in this article are included in the article's Creative Commons licence, unless indicated otherwise in a credit line to the material. If material is not included in the article's Creative Commons licence and your intended use is not permitted by statutory regulation or exceeds the permitted use, you will need to obtain permission directly from the copyright holder. To view a copy of this licence, visit http://creativecommons.org/licenses/by/4.0/. The Creative Commons Public Domain Dedication waiver (http://creativecommons.org/publicdomain/zero/1.0/) applies to the data made available in this article, unless otherwise stated in a credit line to the data. 


\begin{abstract}
(Continued from previous page)
Conclusion: This study found work-related MSDs were prevalent among hairdressers, but the use of healthcare services remains low. Age, length of employment, number of customers served per day, and number of hours spent standing per day to make hair were significantly associated. Therefore, we recommend employers need to develop health and safety programs that account for factors related to the workplaces. The findings also demonstrate that health practitioners would encourage pain management procedures.
\end{abstract}

Keywords: Prevalence, Work-related musculoskeletal disorders, Hairdressers, Ethiopia

\section{Background}

Musculoskeletal disorders (MSDs) are pains that mainly affect body structures such as tendons, muscles, joints, ligaments, nerves, and bones [1-3]. They are usually attributed to years of exposure to events in daily life (unrelated to the workplace) and to injuries caused by accidents at work [1, 4]. Musculoskeletal disorders induced by occupational exposures are the major threats to public health, with a significant effect on workers, employers, and the general population. The conditions contribute to considerable morbidities such as physical injuries and disabilities $[2,3,5]$, a decrease in quality of life [5-9], and a substantial burden for the use of healthcare facilities $[5,7,10]$. Besides, according to the 2016 survey of Global Burden of Disease (GBD), musculoskeletal pains were the leading cause of disability-adjusted life years (DALYs) (61.6\% of years lived with disabilities) [11].

Studies have shown that musculoskeletal disorders related to work are commonly reported and widely documented in various professions, resulting in a considerable loss of productivity $[1,12,13]$. According to the Health and Safety Executive (HSE) survey, in 2017/18, over 469,000 employees experienced work-related musculoskeletal injuries in the UK, accounting for $35 \%$ of all work-related illnesses [1]. Informal/small scale industries in developing countries, including Ethiopia are growing enormously. However, the observance of health and safety regulations are usually neglected, and work environments are arranged to a substandard which make the situation more complicated $[13,14]$. The hairdressing industry is one where the majority of the working population is likely subject to various physical, chemical (hair products), ergonomic, psychosocial, and biological hazards, concomitantly [14-19].

Specific ergonomic hazards such as extended standing, awkward work postures, strenuous and excessive shoulder movements, forceful exertion, and repetitive motion are inherently linked to hairdressing tasks [14, 20-22]. As a result, scholars indicated musculoskeletal pain among hairdressers is recurrently reported. For instance, a study conducted among Taiwanese hairdressers showed the prevalence of pain in shoulder was 91.7, 83.3\% low back, and $75 \%$ neck [23]. Similarly, a study in Nigeria reported the prevalence of $76.3,62.5$, and $46.3 \%$ in low back, shoulder, and neck, respectively [4]. In our previous studies, we found $55.7 \%$ prevalence of back pain, 39.4\% knee/ leg, $25.6 \%$ ankle [24], and 56.7\% upper body [19].

Evidence unveils that the incidence of work-related musculoskeletal disorders is influenced by numerous factors. Accordingly, work-related musculoskeletal pain is notably attributed to socio-demographic characteristics such as gender [3, 25], age [19, 26-28], marital status [27], level of education and experience [29] and income [30]. Moreover, psychosocial characteristics such as work dissatisfaction [31], perceived work stress [32], and time pressure [3] are important factors of workrelated musculoskeletal disorders. Intensive studies have established that occupational/workplace factors such as working hours [16], job tenure [3], work-demand [33], working posture $[4,16,19]$, number of customers serviced per day [4], and shiftwork [27, 33] are the main contributors of work-related musculoskeletal pains. Further, lifestyle behaviors such as physical exercise, alcohol use, and smoking [19] also affect the occurrence of occupational related MSDs significantly.

In Ethiopia, there has been a significant rise in informal industries including hairdressing salons since recent decades [19]. However, the implementation of health and safety regulations is generally fragile. Besides, inspection personnel also usually find it difficult to get access to the industries for regular supervision purposes because of the lack of reliable data available [34]. To date, very limited studies have been conducted in these industries which provide little data for policy conclusions. Therefore, this study aimed to examine the prevalence and associated factors of musculoskeletal disorders, and the use of healthcare services among informal workers in hairdressing salons in Oromia Special Zone Surrounding Finfine, Ethiopia.

\section{Methods \\ Study design}

A cross-sectional

\section{Study period and area}

This study was executed between March and April 2019 at Oromia Special Zone Surrounding Finfine, Ethiopia. The zone is one of the zones of the National Regional State of Oromia, and it was established in 2008 G.C. The 
zone surrounds Addis Ababa, also known as 'Finfinne' in the local language of 'Afan Oromo.' Addis Ababa is the capital of Ethiopia. The city is the administrative hub of the zone. The zone contains ten towns, namely Burayu, Dukam, Galan, Holeta, LagaTafo-LagaDadi, Sebeta, SebetaHawas, Menagesha, Sandafa, and Sululta. Among these, Burayu, Sebeta, Sebeta Hawas, and Sululta were selected by a lottery method for inclusion. According to the 2007 survey of the Central Statistics Agency (CSA) of Ethiopia, the total population of the zone was 794,489 of whom 228,420 were urban residents [35]. There were 2066 hairdressing salons in the zone with 2-4workers at each in the salon during the data collection period.

\section{Source and study populations}

All hairdressers in Oromia Special Zone Surrounding Finfine were the source population whereas the randomly selected hairdressers from the included towns were the study population. Hairdressers who worked at least 12 months before the start of the study were eligible for inclusion, whereas those who had a history of injuries, musculoskeletal disorders, and pregnant women were excluded because they might confound the results.

\section{Sample size determination}

OpenEpi software has been used to calculate the required sample, taking a prevalence of $75.6 \%$ [4], an absolute precision of $4 \%$ with a $\mathrm{CI}$ of $95 \%$ at $\mathrm{Z}=1.96$ critical value and a design effect of 1.5. A $10 \%$ was added for no responses that yielded the final sample size of 699 . We also estimated sample for factors affecting work-related MSDs to ensure the sample is adequate. We performed this using a study in Brazil (80\% proportion with 2.78 odds ratio for not comfortable body posture) [14], and we attained the sample size of 508. Comparing the two sample sizes, a decision has been made on the largest sample already estimated; 699. We employed a systematic random sampling technique to get the participants that were sampled. All the towns were first considered (included in chance) for a random selection, but only four were chosen by chance (lottery method). Because of the feasibility concerns, we included the towns with a lottery method.

\section{Operational definitions}

\section{Work related musculoskeletal disorders}

Is a self-report pain, ache or discomfort in at least two body sites in the past 12 months. The body sites include neck, shoulder, upper back, lower back, hips /thigh, knee/leg, ankle/foot, elbow and wrist/hand [36].

\section{Perceived disability}

A pain disability point score of 3-6 points [37].

\section{Perceived severity}

A pain intensity score of $\geq 50$ or $<3$ disability points [37].

\section{Awkward postures (AP)}

Working with the neck bent without support, working with a bent wrist, working with the back bent without support, squatting and kneeling for two or more hours per day [38].

\section{Repetitive work (RW)}

A work involving repeating the same motion with less than $30 \mathrm{~s}$ or no variation every few seconds for two or more hours per day [38].

\section{Static postures (SP)}

Sitting or standing in a restricted space for two or more hours without changing positions per day [38].

\section{Job satisfaction}

A generic job satisfaction scales core of 32 or above [39].

\section{Job stress}

A workplace stress scale score of 21 or above [40].

\section{Body mass index}

Underweight $=<18.50$; Normal $=18.50-24.99$, and Overweight/Obese $=\geq 25.00$ [19].

\section{Physical exercise}

Performing any kind of sport activity at least two times per week for a duration of $30 \mathrm{~min}$ [41].

\section{Adjustable chair}

Chairs have wheels or castors suitable for the floor surface, have adjustable seat height [42].

\section{Un-comfortable thermal environment}

At least two or more "yes" responses in the thermal comfort factor items [43].

\section{Data collection tools and procedures}

A structured, close-ended, and a pretested questionnaire was used for data collection via a face-to-face interviewadministered technique. We developed the questionnaire after a meticulous review of literature with a slight modification [19, 37, 39, 40, 44]. The standardized Nordic musculoskeletal questionnaire was used for the assessment of musculoskeletal symptoms [44]. We analyzed the perceived satisfaction of hairdressers with the generic job satisfaction questionnaire on the 10-item scale [39]. The perceived jobrelated stress of the participants was collected with the workplace stress questionnaire on the 8-item scale [40]. The perceived severity and disability of musculoskeletal pains have also been evaluated by use of the 7-items Von 
korff et al. [37]. This instrument is measured based on 0 to 10 responses and added together to geta summary score of 100 . The perceived severity of pain was calculated by the formula $=((($ response question 1$)+($ response question $2)+($ response question 3$)) / 3) * 10$; disability score $=((($ response question 5) +(response question 6)+(response question 7)) / 3) * 10 and disability points = (points for disability days or question number 4) + (points for disability score). A final score was categorized into two with a score of $\leq 50$ or disability point $<3=0$ (low severity), a score of $\geq 50$ or disability points $<3=1$ (high severity) and perceived disability $=$ disability points $<3=0$ (low disability) and disability points $\geq 3=1$ (high disability). All the instruments used in the current study have been employed in the previous studies conducted in the country's context $[19,45]$. Detail information on socio-demographic characteristics such as sex, age, religion, educational status, marital status, monthly salary, and work experience were gathered. A workplace-related factors including working hours per day, health and safety training, number of customers per day, work posture, and rest break were also explored. Finally, data on psychosocial factors such the perceived job satisfaction and job stress and behavioral/ individual factors including physical exercise, alcohol use, smoking, and body mass index (BMI) (self-report weight divided by height squared), and history of systemic illnesses were obtained.

\section{Data quality control}

First, we focused on developing the instruments for data collection. As such, the questionnaire was designed in English and translated into local the language 'Afan Oromo' and back to English by 2 independent language experts. Then we employed four trained data collectors (Occupational health and safety experts and Environmental health officers 2 from each) and two supervisors. Data collectors and supervisors were provided with adequate training and instructions on issues related to the clarity of the questionnaire, study aims, confidentiality of information and voluntary participation (consent) of the participants. The principal investigator supervised both the data collectors and supervisors. We also conducted a pretest on $5 \%$ (35 participants) of the sample in another town (Bishoftu) a week before the actual data collection. Based on the pretest, the number of questions and some words difficult to understand were modified.

\section{Data analysis}

Data were entered to and cleaned in Epi-info version 7.2.1.0 and exported to Statistical Package for Social Science (SPSS) version 20 software for analysis. The descriptive findings were presented using percentages, frequency distribution and measures of central tendency. We verified the goodness of model fitness by use of Hosmer and Lemeshow $(p=0.391)$. The reliability of the standardized Nordic Musculoskeletal questionnaire was tested (Cronbach's alpha $=90.93$ ). The 10-items job satisfaction scale questionnaire was examined (Cronbach's Alpha $=0.723$ ). We also examined the 8-items job stress scale questionnaire, and a Cronbach's alpha result found 0.781 . Reliability of the Von korff et al. item employed for the assessment of the perceived disability and severity of pains has also been evaluated (Cronbach's alpha = 0.802). The instruments were, therefore, tolerable for their consistency in repeating what had previously been measured with those tools. A multicollinearity of the variables was evaluated by use of a collinearity check, which was analyzed using a variable inflection factor $($ VIF $<5)$. The associations between the dependent and independent variables were examined using a binary logistic regression analysis. Accordingly, explanatory variables with a $p$-value $<0.2$ in the bivariable analysis were exported to the multivariable logistic regression model to further investigate effects of potential confounders. The significance level was obtained at $\leq 0.05 p$-values with $95 \%$ CI. Adjusted odds ratios were also used to establish strength of the associations.

\section{Results}

\section{Socio-demographic characteristics}

A total of 652 hairdressers were interviewed with a response rate of $93.3 \%$. More than half, $54.9 \%(N=358)$ of the participants were males. Fifty-two percent $(N=339)$ of the respondents aged $>30$ and ranged from 17 to 55 with the mean of 33.19 (Standard deviations (SD) \pm 9.639) years. Regarding educational level, $73.8 \%(N=$ $481)$ attended a secondary school and above. Just lower than half, $47.5 \%(N=310)$ were married (Table 1$)$.

\section{Individual (behavioral) characteristics}

Seventy-three percent $(N=476)$ of the respondents did not use alcohol, whereas $17.8 \%(N=116)$ did. Eighty percent $(N=524)$ of the respondents were non-smokers, 6.4\% $(N=42)$ past smokers, and $13.2 \%(N=86)$ current smokers. About $46 \%(N=298)$ performed physical exercise of whom $6.3 \%(N=41)$ performed one time, $19.2 \%$ $(N=125) 2$ times, and $20.2 \%(N=132) \geq 3$ times per week for at least $30 \mathrm{~min}$. Twenty nine percent $(N=190)$ indicated they had a systemic illness. About $66.6 \%(N=$ $305)$ of the participants perceived low severity pain while $33.4 \%(N=153)$ high. More than two third, $72.1 \%(N=$ $330)$ perceived a low disability pain whereas $27.9 \%(N=$ 128) perceived high.

\section{Workplace characteristics}

Fifty-six percent $(N=365)$ of the participants worked more than $8 \mathrm{~h}$ per day. Lower than half, $48 \%(N=313)$ took safety trainings. Few, 3.7\% $(N=24)$ took more than a rest break of 45-min a day except for a lunch break. 
Table 1 Sociodemographic characteristics of hairdressers, Ethiopia, $2019(N=652)$

\begin{tabular}{|c|c|c|}
\hline Characteristic & Frequency (n) & Percent (\%) \\
\hline \multicolumn{3}{|l|}{ Sex } \\
\hline Male & 358 & 54.9 \\
\hline Female & 294 & 45.1 \\
\hline \multicolumn{3}{|l|}{ Marital status } \\
\hline Married & 310 & 47.5 \\
\hline Single & 256 & 39.3 \\
\hline Divorced & 86 & 13.2 \\
\hline \multicolumn{3}{|l|}{ Religion } \\
\hline Protestant & 307 & 47.1 \\
\hline Orthodox & 208 & 31.9 \\
\hline Muslim & 103 & 15.8 \\
\hline Catholic & 34 & 5.2 \\
\hline \multicolumn{3}{|l|}{ Educational Level } \\
\hline Unable to read and write & 10 & 1.5 \\
\hline Primary school & 161 & 24.7 \\
\hline Secondary school and above & 481 & 73.8 \\
\hline \multicolumn{3}{|l|}{ Monthly salary } \\
\hline$<1800$ ETB & 385 & 59.1 \\
\hline 1800-2350 ETB & 122 & 18.7 \\
\hline$>2350$ ETB & 145 & 22.2 \\
\hline \multicolumn{3}{|l|}{ Work experience } \\
\hline$\leq 5$ years & 342 & 52.5 \\
\hline$>5$ years & 310 & 47.5 \\
\hline \multicolumn{3}{|l|}{ Age } \\
\hline$\leq 30$ years & 313 & 48 \\
\hline$>30$ years & 339 & 52 \\
\hline
\end{tabular}

Keys: ETB Ethiopian birr (currency), N Number, WMSDs Work-related musculoskeletal disorders

The majority, $53.2 \% \quad(N=347)$ of the respondents worked 7 days per week whereas $45.2 \%(N=295) 4-6$ days. Around $39.3 \%(N=256)$ of the hairdressers spent 6-10 $\mathrm{h}$ per day standing at work to make hair. About more than half, $55.2 \%(N=360)$ worked in the same position. In response to the question; the number of customers served in a day, $36.2 \%(N=236)$ indicated that they served lower than 9 customers while $27.9 \%(N=$ 182) $10-15$ customers per day (Table 2 ).

\section{Psychosocial characteristics}

The majority, $68.9 \%(N=449)$ of the participants had a good work relationship with their colleagues and $64.9 \%$ $(N=423)$ with their customer. Almost all, 85.6\% $(N=$ $558)$ had boss at their work of whom $47.1 \%(N=307)$ had a good work relationship with them. More than half, $55.7 \%(N=363)$ were not satisfied with their current job.
Moreover, $48 \%(N=315)$ explained they perceived stress because of their jobs.

\section{Prevalence of work-related musculoskeletal disorders and} its health service use

This study revealed that the overall prevalence of musculoskeletal disorder in the past 12 months at least in two body sites was $70.2 \%(N=458)[95 \% \mathrm{CI}(66.7,73.9)]$ and the previous 7 days prevalence was $55.7 \%(N=364)[95 \%$ CI $(52,59.4)]$. A few, $28.7 \%(n=187)$ of those participants with pains used healthcare services. The body region mostly sited with the symptoms was shoulder, $53.7 \%(n=$ $350)$ followed by neck, $53.4 \%(n=348)$, and $53.2 \%(n=$ 347) low back while $33.4 \%(n=218)$ reported in knee, $41.1 \%(n=268)$ hips/thighs, and $42.9 \%(n=280)$ wrists/ hands (Fig. 1). Of the total respondents with shoulder pain, $45.4 \%(n=159)$ experienced it in the last 7 days, $30 \%$ $(N=105)$ were prevented from their activities and $17.0 \%$ $(N=59)$ visited physician. About $32 \%(N=111)$ of those with neck pain were prevented from their work, $16.1 \%$ $(n=56)$ visited physicians in the past 12 months and $31.4 \%(N=109)$ had experienced it in the last 7 days. Moreover, among the sufferers of elbows/forearms pain, $38.7 \%(N=114)$ experienced it in the past7 days, whereas $38 \%(N=164)$ were prevented from their normal activities and $20.7 \%(N=61)$ visited physicians.

\section{Factors associated with work-related musculoskeletal disorders}

In the bivariable logistic regression analysis, age, physical exercise, educational level, work experience, number of customers in a day and hours spent standing to make hair were associated factors of work-related musculoskeletal disorders. In the multivariable logistic regression model, age, work experiences, number of customers in a day, and hours spent standing to make hair remained significantly associated with work-related musculoskeletal disorders.

The study identified age of the respondents was significantly associated with work-musculoskeletal disorders. The participants in the age group of $>30$ years had 2.7 times higher odds of developing work-related MSDs than those in the age group of $\leq 30$ years [AOR: 2.73; $95 \%$ CI $(2.55,5.46)]$. Those who had a work experience of $>5$ years were 1.5 times higher at risk to develop work-related musculoskeletal disorders compared with those with $\leq 5$ years [AOR: $1.51 ; 95 \%$ CI $(1.03,2.20)$ ].

The chance of developing work-related musculoskeletal disorders was 2.4 times higher for the participants who served $\geq 24$ customers a day than $\leq 9$ customers [AOR: 2.4 ; 95\% CI $(1.35,4.11)]$. The participants who spent $11-15 \mathrm{~h}$ per day standing to make hair were 3.4 times more likely to experience work-related musculoskeletal disorders than who spent 1-5 h [AOR: 3.4; 95\% CI, (2.49,7.77)] (Table 3). 
Table 2 Workplace characteristics of hairdressers, Ethiopia, 2019 $(N=652)$

\begin{tabular}{lll}
\hline Characteristic & Frequency $(n)$ & Percent (\%)
\end{tabular}

Awkward posture/ bending
or twisting/ involved

Yes

No

Hour spent bending/twisting per day

$1-5 \mathrm{~h}$
$\geq 6 \mathrm{~h}$

Work in the same position/ static posture

Yes

No

Involved in repetitive task

Yes

No

Working hours per day

$$
\leq 8 \mathrm{~h}
$$

$>8 \mathrm{~h}$

Working days per week

$$
\begin{aligned}
& \text { 1-3 days } \\
& 4-6 \text { days } \\
& 7 \text { days }
\end{aligned}
$$

Average rest break used per day

$$
\begin{aligned}
& <30 \text { min } \\
& 30-45 \text { min }
\end{aligned}
$$$$
>45 \mathrm{~min}
$$

Adequate light at work

$$
\text { Yes }
$$$$
\text { No }
$$

Work load

Yes

No

Job categories /activities

Washing and cutting

$$
\text { Yes }
$$$$
\text { No }
$$

\section{Designing}

$$
\text { Yes }
$$$$
\text { No }
$$

Rolling/curling/waving

$$
\text { Yes }
$$$$
\text { No }
$$

338

48.2

51.8

31.6

16.4

55.2

69.2

30.8

44

56

1.5

45.3

53.2

347

\begin{tabular}{|c|c|c|}
\hline Characteristic & Frequency (n) & Percent (\%) \\
\hline \multicolumn{3}{|l|}{ Coloring } \\
\hline Yes & 19 & 2.9 \\
\hline No & 633 & 97.1 \\
\hline \multicolumn{3}{|c|}{ Adjustable chair available } \\
\hline Yes & 327 & 50.2 \\
\hline No & 325 & 49.8 \\
\hline \multicolumn{3}{|c|}{ Finger supported scissors } \\
\hline Yes & 465 & 71.3 \\
\hline No & 187 & 28.7 \\
\hline \multicolumn{3}{|l|}{ Thermal comfort } \\
\hline Comfortable & 48 & 7.4 \\
\hline Uncomfortable & 604 & 92.6 \\
\hline \multicolumn{3}{|c|}{ Safety/ergonomic training } \\
\hline Yes & 313 & 48 \\
\hline No & 339 & 52 \\
\hline \multicolumn{3}{|c|}{$\begin{array}{l}\text { Number of customers served } \\
\text { per day }\end{array}$} \\
\hline$\leq 9$ customers & 198 & 30.4 \\
\hline 10-15 customers & 166 & 25.5 \\
\hline $16-23$ customers & 130 & 19.9 \\
\hline$\geq 24$ customers & 158 & 24.2 \\
\hline \multicolumn{3}{|c|}{$\begin{array}{l}\text { Hours spent in standing } \\
\text { position per day }\end{array}$} \\
\hline $1-5$ & 269 & 41.3 \\
\hline $6-10$ & 230 & 35.3 \\
\hline $11-15$ & 153 & 23.4 \\
\hline
\end{tabular}

Table 2 Workplace characteristics of hairdressers, Ethiopia, 2019 ( $N=652)$ (Continued)

\section{Discussion}

So far, occupational-related health conditions of informal workers have been least investigated in Ethiopia. The purpose of this study was to investigate the prevalence and associated factors of work-related musculoskeletal disorders among hairdressers in Oromia Special Zone Surrounding Finfine, Ethiopia. The study also described experiences of the workers on the use of healthcare for pain management. The finding showed that the prevalence of work-related MSDs among hairdressers in the past 12 months was $70.2 \%$ [95\% CI $(66.7,73.9)]$ whereas $55.7 \%$ prevalence was reported during the past 7 days. This implies that work-related musculoskeletal disorders are the priority occupational health problems among informal sectors of hairdressers in Ethiopia. This may be because in Ethiopia, employees of small-scale industries including hairdressers and self-employed workers (as the majority of hairdressers are self-employed) are often rarely considered in health and safety policy actions and plans. Few recently introduced (as promising regulations) on 


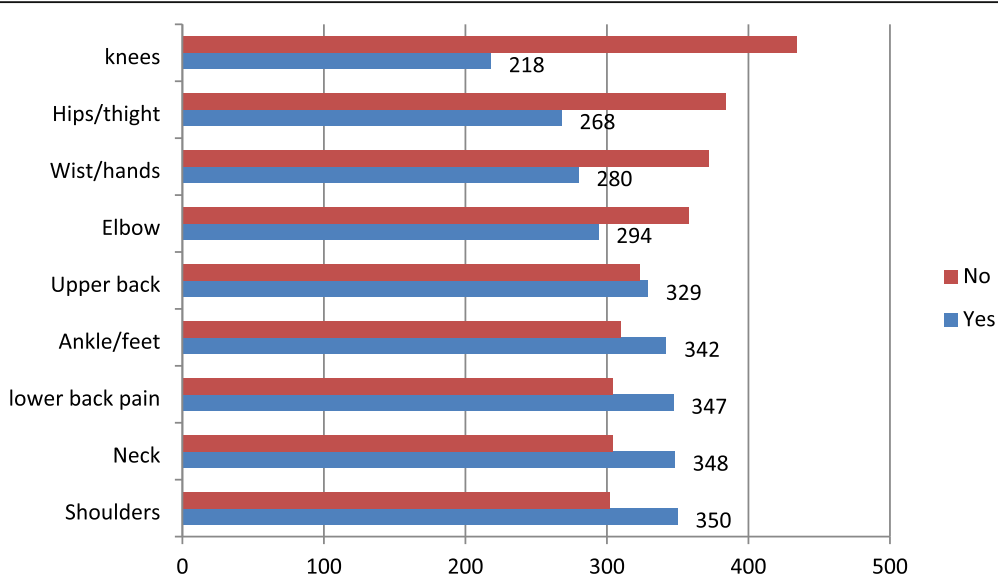

Fig. 1 Prevalence of work-related MSDs by body regions

health and safety issues in the country are also at the earliest stage and informal sectors are often ignored, despite their unremitting growth in number [46].

The prevalence observed in the current study was equivalent to the result in Brazil (71\%) [14]. The inherent nature of work characteristics in informal industries is perhaps similar in every country, irrespective of the efforts to protect workers' health and safety. However, our finding indicates a lower prevalence of musculoskeletal symptoms than a study finding in Nigeria (75.6\%) [4]. The

Table 3 Factors associated with work-related MSDs among hairdressers, Ethiopia, 2019

\begin{tabular}{|c|c|c|c|c|c|}
\hline \multirow[t]{2}{*}{ Characteristic $(N=652)$} & \multicolumn{2}{|c|}{ Work-related MSDs } & \multirow[t]{2}{*}{ COR $(95 \% \mathrm{Cl})$} & \multirow[t]{2}{*}{ AOR $(95 \% \mathrm{Cl})$} & \multirow[t]{2}{*}{$P$-value } \\
\hline & Yes (\%) & No (\%) & & & \\
\hline \multicolumn{6}{|l|}{ Age } \\
\hline$\leq 30$ years & 179(57.2) & 134(42.8) & 1 & 1 & \\
\hline$>30$ years & $279(82.3)$ & $60(17.7)$ & $3.48(2.43-4.98)$ & $2.73(2.55-5.46)$ & $0.0001^{*}$ \\
\hline \multicolumn{6}{|l|}{ Educational level } \\
\hline Unable to read and write & $9(81.2)$ & $1(18.2)$ & $4.12(0.52-32.79)$ & $2.19(0.23-20.99)$ & 0.49 \\
\hline Primary school & 119(75.6) & $42(24.4)$ & $1.29(0.87-1.94)$ & $1.06(0.68-1.64)$ & 0.81 \\
\hline Secondary and Above & $330(67.8)$ & $151(32.2)$ & 1 & 1 & \\
\hline \multicolumn{6}{|l|}{ Work experience } \\
\hline$\leq 5$ years & $217(63.5)$ & $125(36.5)$ & 1 & 1 & \\
\hline$>5$ years & $241(77.7)$ & $69(22.3)$ & $2.01(1.42-2.85)$ & $1.51(1.03-2.20)$ & $0.001^{*}$ \\
\hline \multicolumn{6}{|l|}{ Physical exercise per week } \\
\hline Once per week & $33(80.5)$ & $8(19.5)$ & 1 & 1 & \\
\hline 2 times per week & $91(72.8)$ & $34(27.2)$ & $0.65(0.27-1.54)$ & $0.41(0.28-2.29)$ & 0.69 \\
\hline$\geq 3$ times per week & $84(63.6)$ & $48(36.4)$ & $0.42(0.18-0.99)$ & $0.37(0.17-1.31)$ & 0.15 \\
\hline \multicolumn{6}{|c|}{ Hours spent in standing position per day } \\
\hline $1-5 h$ & 170(63.2) & $99(36.8)$ & 1 & 1 & \\
\hline $6-10 h$ & 154(66.9) & $76(33.1)$ & $1.18(0.82-1.71)$ & $1.12(0.75-1.68)$ & 0.94 \\
\hline $11-15 h$ & 134(87.6) & 19(12.4) & $4.11(2.39-7.05)$ & $3.4(2.49-7.77)$ & $0.0001^{*}$ \\
\hline \multicolumn{6}{|c|}{ Customer attending per a day } \\
\hline$\leq 9$ customers & $151(63.9)$ & $85(36.1)$ & 1 & 1 & \\
\hline 10-15 customers & $122(67)$ & $60(33)$ & $1.15(0.76-1.72)$ & 1.14(0.73-1.78) & 0.57 \\
\hline $16-23$ customers & $74(75.5)$ & $24(24.5)$ & $1.74(1.02-2.95)$ & $1.52(0.07-3.45)$ & 0.06 \\
\hline$\geq 24$ customers & $111(81.6)$ & 25(18.4) & $2.49(1.50-4.16)$ & $2.35(1.35-4.11)$ & $0.001^{*}$ \\
\hline
\end{tabular}

Keys: -*ignificant in multivariate analysis; $N$ Number, OR Odds ratio, CI Confidence interval, WMSDs Work-related musculoskeletal disorders 
possible explanations could be because of discrepancies in workplace illness and injury reporting cultures and procedures, pain perceptions of workers and number of customers served daily.

Our investigation demonstrates that $53.4 \%$ of the participants reported pain in necks, which was comparable to data in Nigeria (46.3\%) [4], Brazil (47\%) [14], and Iran (50.9\%) [47] but higher than another study in Ethiopia (29.3\%) [19]. The current study also revealed that the prevalence of work-related musculoskeletal pain found highest in shoulder, $53.7 \%(n=350)$ than in the other body sites. This is consistent with the data in Brazil (49\%) [14]. The methods of data collection used in the studies were similar which might be the possible reason for this correspondence. However, a lower prevalence rate was detected in the current study than a report in Nigeria (62.5\%) [4] and Taiwan (83.3\%) [23]. The incidence of upper back pain was reported in $50.5 \%$ of the interviewed individuals, which is far higher than the Nigeria (4.6\%) [4] and Iran (39.5\%) [22] reports. Lower than half (45.1\%) of the participants indicated having suffered from pain in their elbows which was far different from literature in Iran (17.6\%). The probable suggestions for the two discrepancies (upper back and elbow) could be because of sample size, data collection technique, perceived severity of pains and injury reporting cultures. We also noticed that $42.9 \%$ of the respondents in the current study located pain in wrists/ hands, which was higher than another report in Ethiopia (32.4\%) [19], the United Kingdom (UK) (25\%) [48] and Iran $(15.1 \%)$ [22]. The inconsistent finding could be as a result of sample size and data collection technique.

Self-report pain in low back was indicated in $53.2 \%$ of the participants in the current investigation. The literature in Nigeria (76.6\%) [4] and Iran (58.7\%) [22] documented higher prevalence than our result did whereas a report in the UK registered a lower prevalence rate (27\%) [48]. Almost half, $52.5 \%$ of hairdressers have also sited pain in knee, which is higher than a study in Iran (41.3\%) and Nigeria (32.8\%) [4].

In our analysis, a significant relation was observed between age of participants and work-related musculoskeletal disorders. This result is supported by findings from the others studies $[19,28,49]$. This might be because the biological structures of human body, particularly those related to bone and muscles would tend to degenerate as age increases. Consequently, functional capacity of the connective tissues and muscle strength would tend to decrease as age increases. This is also evident that as age increases, the likely occurrence of musculoskeletal pains would possibly increase. This explanation agrees with the studies in Greek [50] and the UK [1].

In this study, length of employment has been markedly associated with the development of work-related musculoskeletal pain. The result is congruent to a study conducted in Ethiopia [19], Pakistan [29], Nigeria [51], and Brazil
[14]. This could be speculated that pain development might be related to the cumulative effects of workloads on the musculoskeletal structures when employment duration increases. A study conducted in Finland, however, contradicts this finding [52]. The study argued pains in the musculoskeletal systems likely increase for the newly employed workers (might be because of deficient in adaptation to work environment) than for the experienced ones. Variations in study designs used and the target populations involved in the studies seem to vary those findings. But, the extent to which work acclimatization is applicable to reduce work exposures related to ergonomic hazards remains unclear in that study.

A significant association of hours spent standing and the prevalence of musculoskeletal disorders was detected in the current investigation. This result concords the reports in Malaysia [53] and Brazil [4]. These similarities could be explained in part by that the extended standing might exert stress on the skeletal structures because of the possible increasing pressures on them. A prolonged standing might also bring about muscle stiffness, which in turn would result in impaired muscle functions. A previous survey has also presented a corresponding explanation [19].

The number of customers served in a day was the other significant factors of work-related musculoskeletal disorders. Our result corroborates the report in Nigeria [4]. The increased number of customers served per day would likely increase workload which in turn prohibits workers from utilizing the required rest breaks. Moreover, workers in small scale industries are usually limited in number/work alone, and the lack of support is often prominent which has also been correspondingly explained by a study in Greece [54].

This study plays a vital role to employers and other stakeholders because it assists them to formulate health and safety programs in informal sectors. It also inspires other investigators to further study the relations of a range of workplace factors and the development of pains in musculoskeletal structures. However, due to the relatively large sample size included, we have not performed a posture analysis that could address the degree to which those participants have been exposed to the workplace ergonomic factors. Moreover, because the study used a self-report assessment method, a recall bias has not been ruled out, resulting in under estimation of the result.

\section{Conclusions}

The study found that work-related MSDs were prevalent among hairdressers but the use of healthcare services continues to be low. Age, length of employment, number of customers served per day, and number of hours spent standing per day were significant factors. Therefore, we advise employers need to develop health and safety programs that account for factors relevant to the workplaces. The 
findings also demonstrate that health practitioners would encourage pain management procedures.

\section{Abbreviations}

AOR: Adjusted Odd Ratio; BMI: Body Mass Index; Cl: Confidence Interval; COR: Crude Odd Ratio; ETB: Ethiopia Birr; MSDs: Musculoskeletal Disorders; SD: standard deviations; USA: the United States of America.; SPSS: Statistical Package for Social Science; WMSDs: Work-related Musculoskeletal Disorders

\section{Acknowledgements}

We would like to acknowledge the University of Gondar, College of Medicine and Health Sciences and Comprehensive Specialized Hospital, Institute of Public Health for providing ethical clearance. The authors are also very much appreciative for all the data collectors, supervisors, and the study participants.

\section{Authors' contributions}

THM: Generated the concept of this research paper, wrote up of the research proposal, analyzed the data, involved in presentation and interpretation process of results and discussion, reviewed and finalized the manuscript document, and corresponding author. GGK: Generated the concept of this research paper, wrote up of the research proposal, analyzed the data, involved in presentation and interpretation process of results and discussions and draft the manuscript. JA: Involved in wrote up of the research proposal, analyzed the data, involved in presentation and interpretation process of results and discussions, and reviewed the draft manuscript document. All the authors read and approved the final manuscript. GGK: analyzed the data, involved in presentation and interpretation process of results and discussion, reviewed and finalized the manuscript document.

\section{Authors' information}

THM- MPH in Occupational Health and Safety Management, Assistant Professor of Public Health in Department of Environmental and Occupational Health and Safety, Institute of Public Health, College of Medicine and Health Sciences, University of Gondar, Gondar, Ethiopia.

E-mail: - tajan2022@gmail.com

GGK-MPH in Occupational Health and Safety Management, Health, Safety and Environmental Inspector at Guno Bedele Zone Labor and Social Affairs Office, Oromia National Regional State, Oromia, Ethiopia.

E-mail: - gutetagetachew@gmail.com

JA- MSc in Environmental Health Science, Lecturer in Department of Environmental and Occupational Health and Safety, Institute of Public Health College of Medicine and Health Sciences University of Gondar, Gondar, Ethiopia.

E-mail: -jemberazanaw21@gmail.com

GGK: MPH in Occupational Health and Safety Management, Lecturer in Department of Environmental and Occupational Health and Safety, Institute of Public Health, College of Medicine and Health Sciences University of Gondar, Gondar, Ethiopia.

E-mail: - gebeguyasa4@gmail.com

\section{Funding}

Not applicable since funding was not received from any organization.

\section{Availability of data and materials}

Authors presented the data in the main paper and made available from the corresponding author on a reasonable request.

\section{Ethics approval and consent to participate}

Ethical clearance was obtained from the Institutional Ethical Review Board (IERB) of the University of Gondar, College of Medicine and Health sciences, Institute of Public Health (Reference \#: EOHS/511/2011). We communicated the letter to each owners of the hairdressers selected for inclusion. Then we explained the objectives of the study sufficiently, and we obtained a written informed consent from the respondents. To keep privacy of the information obtained, only aggregate data were used for analysis and interpretations of the results. Participation and withdraw from the study at any time during the data collection was highly respected, and it was based solely on the participants' full consent.

\section{Consent for publication}

Not applicable.

\section{Competing interests}

The authors declare that there are no competing interests.

\section{Author details}

${ }^{1}$ Department of Environmental and Occupational Health and Safety, Institute of Public Health, College of Medicine and Health Sciences, University of Gondar, P.O. Box. 196, Gondar, Ethiopia. ${ }^{2}$ Guno Bedele Zone Labor and Social Affairs Office, Oromia National Regional State, Oromia, Ethiopia.

Received: 27 August 2019 Accepted: 10 May 2020

Published online: 19 May 2020

\section{References}

1. Health and Safety Executive. Work related musculoskeletal disorders in Great Britain (WRMSDs); 2018. Available at: www.hse.gov.uk/statistics/causdis/msd. pdf. Accessed on 5 March 2019.

2. Vieira E, Albuquerque-Oliveira P, Barbosa-Branco A. Work disability benefits due to musculoskeletal disorders among Brazilian private sector workers. BMJ Open. 2011;1(1):e000003.

3. Sulaiman SK, Kamalanathan P, Ibrahim AA, Nuhu JM. Musculoskeletal disorders and associated disabilities among bank workers. Int J Res Med Sci. 2015:3(5):1153-8.

4. Aweto HA, Tella BA, Johnson OY. Prevalence of work-related musculoskeletal disorders among hairdressers. Int J Occup Med Environ Health. 2015;28(3):545-55.

5. Duffield SJ, Ellis BM, Goodson N, Walker-Bone K, Conaghan PG, Margham T, et al. The contribution of musculoskeletal disorders in multimorbidity: implications for practice and policy. Best Pract Res Clin Rheumatol. 2017; 31(2):129-44.

6. Roux CH, Guillemin F, Boini S, Longuetaud F, Arnault N, Hercberg S, et al. Impact of musculoskeletal disorders on quality of life: an inception cohort study. Ann Rheum Dis. 2005;64(4):606-11.

7. Beaudart $C$, Biver $E$, Bruyère $O$, Cooper $C$, Al-Daghri N, Reginster J-Y, et al. Research e: quality of life assessment in musculo-skeletal health. Aging Clin Exp Res. 2018;30(5):413-8.

8. Kyriakopoulos S, Papageorgiou DE, Stroubouki T, Stavropoulou A, Ntinou E, Galanopoulos J, et al. Quality of life of patients with musculoskeletal disorders in a Greek hospital: ethics in biology, engineering and medicine. An Int J. 2013;4(4):269-84.

9. Briggs AM, Cross MJ, Hoy DG, Sanchez-Riera L, Blyth FM, Woolf AD, et al. Musculoskeletal health conditions represent a global threat to healthy aging: a report for the 2015 World Health Organization world report on ageing and health. Gerontologist. 2016;56(suppl_2):S243-55.

10. Woolf AD, Pfleger B. Burden of major musculoskeletal conditions. Bull World Health Organ. 2003;81:646-56.

11. Briggs AM, Woolf AD, Dreinhöfer K, Homb N, Hoy DG, Kopansky-Giles D, et al. Reducing the global burden of musculoskeletal conditions. Bull World Health Organ. 2018;96(5):366

12. Daneshmandi $H$, Choobineh $A$, Ghaem H, Alhamd M, Fakherpour A. Hygiene: the effect of musculoskeletal problems on fatigue and productivity of office personnel: a cross-sectional study. J Prev Med Hyg. 2017:58(3):E252.

13. Etemadinezhad S, Yazdani Charati J. Investigation into the musculoskeletal disorders prevalence and postural assessment among barbers in Sari-2016. Iranian J Health Sci. 2018;6(4):0.

14. Mussi G, Gouveia N. Prevalence of work-related musculoskeletal disorders in Brazilian hairdressers. Occup Med. 2008;58(5):367-9.

15. Abia WA, Fomboh R, Ntungwe E, Abia EA, Serika WA, Ageh MT. Assessment of occupational health hazards awareness and common practices amongst barbers and hairdressers in Cameroon. J Public Health Dev Ctries. 2016;2(1): 94-101.

16. Hakim S, Abdel-Hamid M. Occupational health risks of hairdressers: knowledge, practice and self-reported symptoms. Egypt J Occup Med. 2019; 43(1):161-74.

17. Ferreira AP. An assessment of occupational health risks in female hairdressers forefront to xenobiotics. Braz J Pharm. 2013;94(3):190-8.

18. Nunes IL, Bush P. Work-related musculoskeletal disorders assessment and prevention. Ergonomics. 2012;1:1-30. 
19. Mekonnen TH, Abere G, Olkeba SW. Risk factors associated with upper extremity musculoskeletal disorders among barbers in Gondar town, Northwest Ethiopia, 2018: a Cross-sectional study. Pain Res Manag. 2019; 2019(2019):1-9.

20. Mandiracioglu A, Kose S, Gozaydin A, Turken M, Kuzucu L. Occupational health risks of barbers and coiffeurs in Izmir. Indian J Occup Environ Med. 2009;13(2):92.

21. Kozak A, Wirth T, Verhamme M, Nienhaus A. Toxicology: musculoskeletal health, work-related risk factors and preventive measures in hairdressing: a scoping review. J Occup Med Toxicol. 2019;14(1):1-14.

22. Mahdavi S, Mahdavi M, Safary M, Rashidi R, Dehghani T, Kosari M. Evaluation of the risk of musculoskeletal disorders using rapid entire body assessment among hairdressers in Khorramabad, Iran, in 2014. J Occup Health Epidemiol. 2015;2(3):138-45.

23. Fang $\mathrm{H}-\mathrm{L}$, Chen $\mathrm{RC}$, Fang $\mathrm{H}-\mathrm{P}, \mathrm{Xu} \mathrm{Q}$. An ergonomic approach to an investigation into the risk factors leading to work-related musculoskeletal disorders for Taiwanese hairdressers. Proceed Int Assoc Soc Design Res IASDR. 2007:49:1-10.

24. Mekonnen $\mathrm{TH}$. The magnitude and factors associated with work-related back and lower extremity musculoskeletal disorders among barbers in Gondar town, Northwest Ethiopia, 2017: a cross-sectional study. PLoS One. 2019;14(7):e0220035.

25. Devreux I, Al-Awa B, Mamdouh K, Elsayed E. Relation of work-related musculoskeletal disorders and over-commitment of rehabilitation staff in Saudi Arabia. Life Sci J. 2012;9(3):781e785.

26. Collins RM, Janse Van Rensburg DC, Patricios JS. Common work-related musculoskeletal strains and injurie. S Afr Fam Pract. 2011;53(3):240-6.

27. Ahmadi M, Rezaiee J, Hashemian AH. Prevalence and risk factors of low Back pain among nurses in an Iranian hospital, (Kermanshah, 2012). Adv Biol Res. 2014:8(4):168-70.

28. Kaushik A, Patra P. Upper extremity and neck disability in male hairdressers with concurrent changes in pinch strength: an observational study. Healthline. 2014;5:46-52.

29. Ayub Y, Shah ZA. Assessment of work related musculoskeletal disorders in manufacturing industry. J Ergon. 2018;8(3):1-5.

30. Ajslev JZN, Persson R, Andersen LL. Treatment: associations between wage system and risk factors for musculoskeletal disorders among construction workers. Pain Res Treat. 2015:2015:1.

31. Lachowski S, Choina P, Florek-Łuszczki M, Goździewska M, Jezior J. Dissatisfaction with work as a risk factor of musculoskeletal complaints among foresters in Poland. Ann Agric Environ Med. 2017;24(4):706-11.

32. Khandan M, Momenyan S, Khodabandeloo M, Koohpaei A. Relationship between job stress and ergonomic behavior with musculoskeletal disorders in an auto-part production company. Arch Hyg Sci. 2018;7(1):23-31.

33. Raithatha AS, Mishra DG. Musculoskeletal disorders and perceived work demands among female nurses at a tertiary care hospital in India. Int J Chronic Dis. 2016:2016:1-6.

34. Deribie E, Studies D. Women in the informal sector: evidence from southwestern Ethiopia. Int J Peace Dev Stud. 2012;3(6):112-7.

35. Tadesse E, Imana G. Prospects and challenges of urbanization on the livelihood of farming community surrounding Finfinne. Am Res J Humanit Soc Sci. 2017;3(1):2378-7031.

36. Aghilinejad M, Choobineh A, Sadeghi Z, Nouri M, Ahmadi AB. Prevalence of musculoskeletal disorders among Iranian steel workers. Iran Red Crescent Med J. 2012:14(4):198.

37. Von Korff M, Ormel J, Keefe FJ, Dworkin SF. Grading the severity of chronic pain. Pain. 1992;50(2):133-49.

38. Kunda R, Frantz J, Karachi F. Prevalence and ergonomic risk factors of workrelated musculoskeletal injuries amongst underground mine workers in Zambia. J Occup Health. 2013;55(3):211-7.

39. Macdonald S, Macintyre P. The generic job satisfaction scale: scale development and its correlates. Empl Assistance Q. 1997;13(2):1-16.

40. The Marlin Company NH, CT, and the American Institute of Stress, Yonkers, NY, The Workplace Stress Scale ${ }^{T M}$. Available at: https://teorionline.files.wordpress. com/2011/04/unit-3-the-workplace-stress-scale.pdf. Accessed on 10 June 2019.

41. Rolander B, Bellner A-L. Experience of musculo-skeletal disorders, intensity of pain, and general conditions in work--the case of employees in non-private dental clinics in a county in southern Sweden. Work. 2001:17(1):65-73.

42. Kee A. Collusive pricing under the commerce act 1975. Victoria U Wellington L Rev. 1984;14:183.
43. Nicol F, Humphreys M. Maximum temperatures in European office buildings to avoid heat discomfort. Sol Energy. 2007:81(3):295-304.

44. Kuorinka I, Jonsson B, Kilbom A, Vinterberg H, Biering-Sørensen F, Andersson G, et al. Standardised Nordic questionnaires for the analysis of musculoskeletal symptoms. Appl Ergon. 1987;18(3):233-7.

45. Mekonnen $\mathrm{TH}$, Yenealem DG. Factors affecting healthcare utilization for low back pain among nurses in Gondar town, Northwest Ethiopia, 2018: a crosssectional study. BMC Res Notes. 2019;12(185):1-6.

46. Tafese A, Nega A, Kifle M, Kebede W. Predictors of occupational exposure to neck and shoulder musculoskeletal disorders among sewing machine operators of garment industries in Ethiopia. Science J Public Health. 2014; 2(6):577-83

47. Khandan M, Toranjian F, Koohpaei A. Musculoskeletal disorders assessment and posture analysis by LUBA among female hairdressers in Tehran, 2015. Arch Hyg Sci. 2017;6(1):26-31.

48. Bradshaw L, Harris-Roberts J, Bowen J, Rahman S, Fishwick DJOM. Selfreported work-related symptoms in hairdressers. Occup Med. 2011;61(5): $328-34$

49. Singh V, Goyal N, Singh A, Bhatty SM, Deane A, Prakash JS. Upper limb musculoskeletal disorders associated with computer usage in health-care professionals. Int J Med Sci Public Health. 2015;4(11):1615-20.

50. Okunribido $\mathrm{OO}$, Wynn T, Lewis D. Are older workers at greater risk of musculoskeletal disorders in the workplace than young workers?-a literature review. Occup Ergon. 2011;10(1, 2):53-68.

51. Ogundele OA, Afolabi OT, Fehintola FO, Olorunsola A, Adelosoye A. Prevalence and management practices of low Back pain among commercial motorcyclists in llesa southwest, Nigeria. Science. 2017;5(3):186-91.

52. Häkkänen M, Viikari-Juntura E, Martikainen R. Job experience, work load, and risk of musculoskeletal disorders. Occup Environ Med. 2001;58(2):129-35.

53. Soe KT, Laosee O, Limsatchapanich S, Rattanapan C. Ergonomics: prevalence and risk factors of musculoskeletal disorders among Myanmar migrant workers in Thai seafood industries. Int J Occup Saf Ergon. 2015;21(4):539-46.

54. Tsigonia A, Tanagra D, Linos A, Merekoulias G, Alexopoulos E. Health p: musculoskeletal disorders among cosmetologists. Int J Environ Res Public Health. 2009;6(12):2967-79.

\section{Publisher's Note}

Springer Nature remains neutral with regard to jurisdictional claims in published maps and institutional affiliations.

Ready to submit your research? Choose BMC and benefit from:

- fast, convenient online submission

- thorough peer review by experienced researchers in your field

- rapid publication on acceptance

- support for research data, including large and complex data types

- gold Open Access which fosters wider collaboration and increased citations

- maximum visibility for your research: over $100 \mathrm{M}$ website views per year

At $\mathrm{BMC}$, research is always in progress.

Learn more biomedcentral.com/submission 